\title{
Os Agricultores Familiares como Réus em PROCESSOS AMBIENTAIS: REFLEXÓES ACERCA DO PODER SIMBÓLICO DO DIREITO
}

\author{
Marlene de Paula Pereira* \\ Maria Izabel Vieira Botelho**
}

1 Introdução. $2 \mathrm{O}$ que revelam os autos. 3 Reflexões a partir das consultas processuais. 4 O poder simbólico do direito e os reflexos sobre os meios de vida dos agricultores familiares. 5 Conclusões. Referências.

\section{RESUMO}

Com frequência, os agricultores familiares enfrentam problemas relacionados à legislação ambiental. $O$ presente artigo tem por objetivo refletir a respeito das consequências decorrentes dos processos judiciais na vida desses agricultores. As metodologias utilizadas foram a consulta processual e as entrevistas. Os principais resultados revelam que a condição de vulnerabilidade que atinge esses agricultores, do ponto de vista social e econômico, estende-se até o campo judicial. Apesar de haver o pressuposto de que a Justiça busca enfrentar as questões com isonomia, constatou-se que os grupos econômica e socialmente mais frágeis são também mais fortemente atingidos com a solução da lide.

Palavras-chave: Legislação ambiental. Agricultores familiares. Processos judiciais. Poder simbólico.

\section{INTRODUÇÃO}

O Direito possui uma função primordialmente reguladora, mas também guarda em si uma dimensão simbólica, que decorre da força com que se impõe sobre os diversos grupos de indivíduos, em seus diferentes lugares sociais. A lei interfere diretamente sobre os meios de vida dos agricultores familiares, visto que, à medida que regulam a vida cotidiana, interferem na maneira como as pessoas se comportam, impondo restrições e trazendo consequências.

Por enfrentarem grande dificuldade de acesso à informação e aos mecanismos de defesa, com frequência, os agricultores familiares são autuados e condenados ao pagamento de multas, celebram termo de ajustamento de conduta e, algumas vezes, até mesmo respon-

* Professora do Instituto Federal de Educação, ciência e tecnologia do Sudeste de MG, campus Barbacena. Bacharela em Direito- UFV. Mestre em Direito- UERJ. Doutora em Extensão Rural - UFV. E-mail: < depaulamarlene@yahoo.com.br>.

** Pós-Doutora em Wageningen University. Professora Associada do Departamento de Economia Rural da Universidade Federal de Viçosa. E-mail: <mbotelho@ufv.br>. 
dem a processos judiciais. Esses processos judiciais, que serão objeto de estudo deste artigo, revelam o quanto tais agricultores se encontram em situação de desvantagem em relação a outros segmentos e o quanto o Direito pode ser um instrumento de poder.

Desse modo, propõe-se uma análise do Direito entendendo o âmbito jurídico como um campo, na acepção de Bourdieu. Segundo Bourdieu, o campo é um espaço de disputas de poder entre grupos. Cada grupo possui um capital, que, para o autor, representa os interesses postos em jogo. O conceito de capital inclui, além do aspecto econômico, que compreende a riqueza material, o dinheiro, as ações etc. (bens, patrimônios, trabalho), o aspecto do capital cultural, que compreende o conhecimento, as habilidades, as informações; o capital social, correspondente ao conjunto de acessos sociais, que compreende o relacionamento e a rede de contatos; e o capital simbólico, que é uma síntese dos demais, correspondente ao conjunto de rituais de reconhecimento social, e que compreende o prestígio, a honra.

A metodologia empregada nesta pesquisa foi a análise processual e a realização de entrevistas. Foram analisados 148 dos 240 processos/procedimentos ambientais em curso na Comarca de Viçosa, no período de 2011 a 2013. Chegou-se a esse quantitativo por meio do cálculo da amostra válida. Esclarece-se que a análise da totalidade dos casos se torna praticamente impossível, no período de tempo da pesquisa, visto que os processos/procedimentos tramitam de uma instância para outra, de um órgão para outro para que sejam feitas análises, pareceres, e, desse modo, seriam necessárias várias outras visitas para conseguir ter acesso a todos os autos.

As pesquisas foram realizadas na $2^{\mathrm{a}}$ Promotoria Cível e na $1^{\mathrm{a}}$ e $2^{\mathrm{a}}$ varas criminais da Comarca de Viçosa. Na Promotoria, foram analisados os Termos de Ajustamento de Conduta, as Ações de Execução dos Termos de Ajustamento de Conduta, os Inquéritos Civis e as Ações Civis Públicas propostas pelo Ministério Público.

Na $1^{\text {a }}$ Vara Criminal, foram analisados os processos que seguem o rito ordinário para onde são destinados os processos referentes a crimes cujas penas máximas sejam superiores a dois anos. Poucos processos por crimes ambientais são processados nessa vara, visto que a maior parte dos crimes previstos na lei de crimes ambientais estipula penas máximas inferiores a dois anos. $\mathrm{Na} 2^{\mathrm{a}}$ Vara Criminal, foram analisados os processos criminais que se enquadram na categoria de "causas de menor potencial ofensivo", considerados estes os crimes e as contravenções penais cujas penas máximas não sejam superiores a dois anos de privação de liberdade. Estes representam a maior parte dos casos em estudo.

Quanto às entrevistas, foram realizadas entrevistas semiestruturadas, feitas com agricultores familiares e com agentes públicos. De acordo com Lakatos e Marconi, ${ }^{1}$ a entrevista é o procedimento em que o entrevistador se coloca face a face com o entrevistado, do qual busca obter informações que não possui sobre determinado assunto. É uma conversa metódica, que segue uma diretriz previamente estabelecida, uma estratégia metodológica que deve ser adequada ao objeto da pesquisa. Para a pesquisa aqui relatada, foram entrevistados 
25 agricultores que desenvolvem suas atividades nos municípios que compõem a Comarca de Viçosa e oito agentes públicos.

A realização das entrevistas ocorreu durante o mês de maio de 2015. O número de 25 entrevistados foi aleatório. Os critérios utilizados para selecionar os entrevistados foram que fosse agricultor familiar e residisse em um dos municípios que compõem a Comarca de Viçosa. Ressalta-se que os agricultores familiares entrevistados não estão diretamente relacionados aos processos analisados. Existem algumas coincidências (pessoas entrevistadas que estão respondendo a processos que foram analisados), mas há outros que já foram autuados pela prática de infrações ambientais, mas cujo processo não foi analisado, e outros, ainda, que afirmaram nunca terem tido problemas dessa natureza. Como um dos objetivos da pesquisa foi analisar as consequências que um processo pode trazer em relação ao modo como esse infrator passa a ser visto pelo grupo social, tornou-se importante ter, também, a participação de pessoas que nunca tiveram problemas com a justiça.

Quanto aos agentes públicos, foram entrevistados oito representantes, que foram os seguintes: dois policiais ambientais, dois técnicos do Instituto Estadual de Florestas (IEF), um promotor, um juiz, o secretário do meio ambiente, um técnico da Empresa de Assistência Técnica e Extensão Rural do Estado de Minas Gerais (Emater).

O artigo está dividido da seguinte maneira: na primeira parte, serão apresentados os dados obtidos nas consultas processuais, em seguida, serão feitas reflexões a respeito do que foi constatado nas análises dos processos e, por fim, serão feitas considerações acerca do poder simbólico do Direito, com apoio nas ancoragens teóricas escolhidas. Algumas conclusões encerram o trabalho.

\section{O QUE REVELAM OS AUTOS}

$\mathrm{Na}$ Comarca de Viçosa, em geral, a autuação é feita pela Polícia Militar do Meio Ambiente. Os policiais chegam ao local do fato por meio de denúncia, na maior parte das vezes, ou por meio de policiamento ostensivo, ou seja, do trabalho normal de ronda. Constatada a infração, a polícia notifica o infrator a respeito da instauração de um procedimento administrativo, que, geralmente, tem como consequência a aplicação de uma multa. $O$ boletim de ocorrência, lavrado na hora, é encaminhado para a Delegacia da Polícia Civil e para o Ministério Público Estadual.

Cabe ao delegado da Polícia Civil analisar se o fato constitui crime ambiental. Se constituir, deverá ser iniciado um inquérito policial. Concluído o inquérito, este deverá ser encaminhado ao Ministério Público, órgão responsável para propor a ação penal. O processo surge com a ação penal, pois, ao dar início a ela, o conflito é levado à apreciação do Poder Judiciário para que o juiz decida se houve crime e se a pessoa acusada deve ser punida.

Paralelamente a isso, o Ministério Público analisa, ainda, se o fato causou dano ambiental. Se tiver causado, poderá optar entre propor um termo de ajustamento de conduta 
(TAC) ou iniciar uma ação civil pública. O Ministério Público tem competência ainda para iniciar inquérito civil para apuração de dano ambiental, independentemente de ocorrência de crime ou infração ambiental. Nesses casos, o fato chega ao conhecimento do promotor por meio de denúncia. Esses inquéritos civis podem ou ser arquivados, ou resultar em termos de ajustamento de conduta ou ensejar a propositura de ação civil pública.

A possibilidade de mais de um desdobramento da infração ambiental é um dos aspectos mais difíceis de serem compreendidos pelos agricultores, pois, muitas vezes, eles são autuados administrativamente e acreditam que o problema será totalmente solucionado com o pagamento da multa. Entretanto, após o pagamento, são surpreendidos com uma notificação para que compareçam ao fórum para realizar um TAC ou recebem uma citação judicial que informa que foi instaurado um processo em que ele é réu. A sensação dos agricultores é a de que estão sendo punidos duplamente ou triplamente pelo mesmo fato.

De acordo com a lei, é possível apresentar defesa contra o auto de infração, no prazo de 20 (vinte) dias, contados da data da notificação. Essa defesa poderá ser elaborada pelo próprio autuado ou por um advogado. Cabe ao autuado a prova dos fatos alegados. Entretanto, as provas propostas pelo autuado poderão ser recusadas, mediante decisão fundamentada da autoridade competente.

Após julgamento da defesa apresentada, o autuado receberá, em sua residência, uma correspondência, contendo um ofício que informará sobre a resposta da defesa. Caberá, ainda, o recurso que poderá ser apresentado no prazo de 30 (trinta) dias, contados da data da notificação do autuado do julgamento da defesa. O recurso também poderá ser elaborado pelo próprio autuado ou por advogado.

De acordo com o art. 68 do Decreto n ${ }^{\circ}$ 44.844/08, inciso I, ${ }^{2}$ poderá haver a redução do valor da multa aplicada, se o interessado comprovar a existência de uma das situações elencadas nos artigos, como a comunicação imediata do dano ou perigo à autoridade ambiental ou a colaboração do infrator com os órgãos ambientais na solução dos problemas advindos de sua conduta.

Embora a legislação deixe claras essas possibilidades, dado o grau de desinformação existente entre os agricultores, a apresentação de defesa e de recurso pelo próprio autuado é muito pouco utilizada. Essa pressuposição foi confirmada pelos técnicos do Instituto Estadual de Florestas (IEF), em entrevista realizada em abril de 2015. Segundo o analista ambiental do IEF, "a maior parte dos agricultores autuados paga a multa, sem contestações, de forma parcelada." 3 Sr. Daniel, morador de Córrego Fundo, Viçosa-MG, é um exemplo que parece representar o comportamento comum entre os agricultores da região em relação ao pagamento de multas. Disse ele: "Paguei $R \$ 6.000,00$ porque não ajustei advogado. Depois me falaram que, se tivesse arrumado advogado, a multa tinha diminuído. Mas eu não arranjei não, porque eu não preciso de advogado. Pra quê advogado? Eu não matei ninguém [...]." 
A partir da fala desse agricultor, duas observações podem ser feitas: a primeira vai ao encontro do estudo de Woortmann, de acordo com o qual a honestidade é um valor a que o camponês dá muita importância. ${ }^{4}$ Nesse sentido, "demandar na justiça" é algo que só deve ocorrer quando não puder ser evitado, pois remete à prática de uma má conduta. Dessa percepção decorre a segunda observação, que aponta para o significado social e psicológico do processo na vida desses sujeitos, pois, muito além de ser um contratempo, implica deduções a respeito do indivíduo.

Ainda sobre a utilização dos recursos, observa-se que somente aqueles que detêm informações suficientes para se defenderem, seja sozinhos, seja por meio de serviços especializados, utilizam esses instrumentos legais. Mais uma vez, fica evidenciado o fato de que, embora existam previsões legais no sentido de facilitar a resolução dos problemas de irregularidade, existe uma parcela significativa de cidadãos que permanece excluída do exercício pleno desses direitos. Considerando a acepção ampla de meios de vida, em que recursos ou ativos são também os acessos e as oportunidades, fica claro que grupos social e economicamente vulneráveis, como é o caso dos agricultores familiares, encontram mais dificuldades para usufruírem as garantias legais e jurídicas.

As autoridades se esforçam para atribuir aos agricultores a responsabilidade por não utilizarem as concessões dadas pela lei e por não pleitearem as políticas de que necessitam, afirmando serem os agricultores pessoas "caladas e pouco participativas." Disse o promotor de justiça da Comarca: "os agricultores não são organizados, e, mesmo quando conseguem se organizarem, de alguma maneira, os representantes têm pouca instrução."

Na Comarca de Viçosa, durante o período de 2011 a 2013, considerando os 240 procedimentos em curso, 65,8\% resultaram em TAC. Destes, 33,5\% foram cumpridos e 66,5\% tiveram desdobramentos judiciais, com propositura de ações. Logo, não se pode afirmar que a realização do acordo extrajudicial tenha amenizado a situação do agricultor, evitando que este tenha desgastes decorrentes da lentidão e da burocracia da Justiça, pois a quantidade de acordos que não foram cumpridos é grande. As principais razões que justificam o descumprimento dos TAC são as dificuldades em cumprir as medidas e o custo que elas envolvem.

Quanto ao período médio para que a questão seja solucionada por meio de TAC, observou-se que, entre a ocorrência do fato e a realização do acordo, decorrem, em média, 2 anos. Entre a realização do TAC e o termo final do processo decorrem, em média, 3 anos, totalizando um período de duração médio para o processo de 5 anos, desconsiderando eventuais recursos. Esse prazo pode variar de acordo com as especificidades do caso, mas se pôde notar que o fator que mais interfere no tempo de duração do processo é a realização da perícia. De acordo com informações obtidas nos próprios autos e confirmadas por funcionários estaduais, a estrutura dos órgãos técnicos estaduais responsáveis pela perícia encontra-se bastante deficitária, de modo que os agentes são insuficientes para o número de solicitações feitas pela Justiça. 


\section{REFLEXÕES A PARTIR DAS CONSULTAS PROCESSUAIS}

Nesta seção, será feita uma análise dos dados apresentados anteriormente, entendendo o âmbito jurídico como um campo, na acepção de Bourdieu, segundo o qual o campo é um espaço de disputas de poder. ${ }^{5}$ De acordo com o autor, cada grupo possui um capital. Este inclui, além do aspecto econômico, o aspecto cultural, que abrange o conhecimento, as habilidades, as informações; o aspecto social, correspondente ao conjunto de acessos sociais, que inclui o relacionamento e a rede de contatos; e o aspecto simbólico, que é uma síntese dos demais, correspondente ao conjunto de rituais de reconhecimento social.

Segundo Bourdieu, existe uma conexão entre o campo e o habitus. O habitus deve ser visto "como um conjunto de esquemas de percepção, apropriação e ação que é experimentado e posto em prática pelo indivíduo." Esse autor, em outro estudo, esclarece que o habitus "é adquirido por aprendizagem e funciona como um sistema de esquemas geradores de estratégias."

O habitus assegura a reprodução das relações sociais, pois o indivíduo interioriza normas e valores e reproduz as relações sociais hierarquizadas já construídas. Em geral, o grupo dominante forma o habitus, estabelecendo o que deve ser entendido como o senso comum. Uma vez internalizada a hierarquia, o habitus se torna ainda mais homogêneo, dada a impossibilidade de tais indivíduos perceberem a existência dos grupos de interesse no seio social. A adesão ou aceitação dos dominados das regras e das crenças partilhadas como se fossem "naturais" e a incapacidade crítica de reconhecer o caráter arbitrário de tais regras impostas pelas autoridades dominantes de um campo é chamada por Bourdieu de "dominação consentida" e reflete um tipo de "violência simbólica."

De acordo com Bourdieu, ${ }^{9}$ na sociedade, existem os grupos dominantes e os dominados, e as instituições têm um papel importante para a perpetuação da dominação. Assim, igrejas, escolas, famílias contribuem para o processo de dominação porque reproduzem o habitus criado pelo grupo dominante. Considerando a esfera judicial como um campo, é possível perceber a existência de um habitus. Por meio deste, os dominantes impõem um conjunto de posturas que os dominados passam a compreender como aceitáveis. Tais posturas são continuamente reproduzidas, e, dessa forma, ocorre a manutenção do sistema.

O poder simbólico, de acordo com Bourdieu, é "o poder invisível o qual pode ser exercido dessa maneira com cumplicidade daqueles que não querem saber que lhe estão sujeitos ou mesmo que o exercem." 10 O autor entende que "os sistemas simbólicos - como arte, religião e língua - têm função importante na reprodução da ordem social.” Essa reprodução da ordem por influência das produções simbólicas configura a existência de ideologias, que são, para o autor, "formações capazes de apresentar interesses particulares como se fossem universais e que, desse modo, influem sobre a função política do sistema simbólico."11

De acordo com Bourdieu, as teorias que buscam justificar o Direito como uma ciência que encontra fundamento em si próprio são a clara demonstração do poder simbólico que 
esse campo possui, pois o consideram independente e desvinculado de contextos sociais e históricos. ${ }^{12}$ Os conflitos e argumentos do cotidiano são vistos como aquém da lei e demasiadamente triviais. No mesmo sentido, Santos afirma que "o pensamento da dogmática jurídica sublima, mediante sucessivas próteses técnicas, tudo o que existe de quotidiano e de vulgar."13

Em lugar de buscar compreender o contexto social e histórico do fato que está sendo julgado, com frequência, o Direito busca a solução em precedentes ou decisões anteriores, em uma pressuposição de que aquilo que já foi decidido é o que representa o justo, o adequado. De acordo com Bourdieu, "a busca do precedente é, para o pensamento jurídico, uma forma de afirmação da autonomia do direito em relação às questões sociais ou históricas." ${ }^{14}$ Dessa forma, as decisões vão sendo padronizadas, e o poder da instituição é reafirmado. Entretanto, com isso, o Direito perde o caráter de instrumento de transformação social. Nesse sentido, Dworkin afirma que "o julgador deve deixar de ser um simples aplicador de normas, para ser uma ferramenta na construção do direito." ${ }^{15}$ De acordo com ele, "o direito nasce de um processo de construção e justificação e não da reprodução de um passado preestabelecido, pois o julgamento feito a partir da reprodução de outras decisões, sem o estudo atento do caso concreto, representa a incidência da violência da autoridade envolvida."16

Na mesma linha, Derrida afirma que "o julgador não pode agir como uma máquina de calcular porque o alcance do justo está muito distante dessa tarefa, de cálculo, pois cada exercício da justiça como direito só poderá ser justo se for um julgamento novo." ${ }^{17}$ Barroso também afirma que os casos cuja solução não se encontra pré-pronta no ordenamento jurídico exigem uma atuação criativa do intérprete, baseada nas orientações constitucionais. Ele observa que "não foi o Direito e a interpretação constitucional que se tornaram mais complicados, mas a vida que ficou mais complexa, exigindo categorias jurídicas mais sofisticadas e sutis." 18

A linguagem judiciária repleta de erudições e expressões em latim é uma manifestação do poder simbólico do Direito. Mas o discurso jurídico é composto de uma série de outros elementos que contribuem para enfatizar a força da instituição. Bourdieu menciona um conjunto de características sintáticas tais como construções passivas, frases impessoais, recurso ao verbo no indicativo, emprego de verbos atestativos e na terceira pessoa do singular que são comumente utilizadas para caracterizar a neutralidade e a impessoalidade que se espera de um enunciado da justiça. ${ }^{19}$

Para pensar a respeito do poder embutido no discurso jurídico, é importante esclarecer o que está sendo compreendido como "discurso" e o que seria o "exercício do poder". Para Meurer, "discurso é o conjunto de afirmações que, articuladas através da linguagem, expressam os valores e significados de um grupo social." ${ }^{20}$ Sendo assim, para ele, o discurso seria o conjunto de valores e significados por trás do texto. A respeito do exercício do poder, seguiu-se a linha de pensamento de Foucault, para quem o exercício do poder é um modo 
de ação de uns sujeitos sobre as ações de outros. ${ }^{21}$ De acordo com esse autor, os efeitos de poder são constituídos nas relações de força entre os sujeitos desiguais, seja pela situação de cada um, seja pelo potencial de recursos que possuem (sejam eles econômicos, militares, de informação).

Quando uma questão chega ao Poder Judiciário, em regra, existe um conflito de interesses, em que os dois lados tentam mostrar quem tem razão, apresentando suas provas. Cabe ao juiz analisar todo o exposto, identificar com quem está o direito, encontrar a norma aplicável ao caso e solucionar o problema. O objetivo do processo, portanto, à luz do princípio da dignidade humana, é, a partir das provas produzidas, fazer com que o juiz se aproxime ao máximo do que de fato ocorreu. Mas, a partir das provas produzidas nos autos, é possível chegar à certeza quanto à verdade dos fatos? Adota-se, aqui, a premissa de que a verdade é sempre uma construção social. ${ }^{22}$ De acordo com Foucault, a verdade é um conjunto de procedimentos regulados para a circulação e o funcionamento dos discursos e está ligada a sistemas de poder que a produzem e apoiam e a efeitos de poder que a reproduzem e são induzidos por ela. ${ }^{23}$

De acordo com Foucault, as relações de poder utilizam o Direito para criar discursos de verdade. ${ }^{24}$ Por ser o direito o discurso da verdade, e a verdade criadora do Direito, Foucault busca demonstrar que o Direito, em sua capilaridade, fomenta relações de sujeição. $O$ Direito deve ser visto como um procedimento de sujeição que ele desencadeia, e não como uma legitimidade a ser estabelecida. Para Bourdieu, "o direito é a forma por excelência do discurso atuante, capaz, por sua própria força, de produzir efeitos." 25

O poder não é somente aquele soberano que emana do povo (art. $1^{\circ}$, parágrafo único, da CF/1988); ${ }^{26}$ ele é também constituído por práticas sociais concretas. De acordo com Foucault, o poder é relacional e só se constitui em uma rede de atores sociais na medida em que se faz uso dele..$^{27} \mathrm{O}$ poder circula em rede por todo o meio social, agindo sobre o corpo e construindo subjetividades, tendo característica, ao mesmo tempo, de um poder disciplinar, que age sobre a individualidade; e de um biopoder que age sobre a vida e sobre a coletividade.

Vianna propõe pensar os autos processuais, em termos metodológicos, como "um conjunto de relatos convertidos em 'depoimentos', escritos por um mecanismo de controle burocrático e de construção de afirmação de autoridade fundamentais para a produção de uma decisão judicial." ${ }^{28}$ Nesse sentido, "um auto processual se constitui como resultado do confronto de posições de autoridade entre os que depõem e os que são responsáveis em traduzir as falas em termos da universalidade jurídica." ${ }^{29}$

Os técnicos do Judiciário têm a função de ouvir o depoente e transcrever a fala de acordo com o jargão forense. Posteriormente, esses trechos serão aproveitados para a confecção da sentença. Portanto, assim como os depoentes selecionam o conteúdo de suas falas, os técnicos da justiça também escolhem o que registrar. Segundo Rinaldi, "em geral, procuram produzir um discurso capaz de trazer benefícios no âmbito da decisão judicial." ${ }^{30}$ 
Foucault, ao comentar esse aspecto, observa como o sistema processual vigente atribui poder aos agentes estatais, pois eles são responsáveis por transcrever a fala dos depoentes e, a partir desses relatos, produzir a sentença. ${ }^{31}$ Foucault ressalta que a observação não se mostra contra os técnicos ou as suas técnicas, e sim contra o poder que possuem em influenciar as decisões do Judiciário. ${ }^{32}$ No mesmo sentido, Bourdieu afirma que, por meio das instituições, os agentes desempenham seus papéis na sociedade, reforçando o habitus instituído e promovendo a sua internalização. ${ }^{33}$

Existe um provérbio originado do Direito Romano que afirma que o que não está nos autos não está no mundo. Essa premissa ressalta a necessidade de o julgador ater-se às provas produzidas para proferir sua decisão, reforçando que o que não estiver nos autos processuais não interessa ao debate processual. Portanto, como regra, do ponto de vista da justiça, o que importa é o que está no processo, ou seja, o discurso construído. Nesse sentido, Foucault afirma que o inquérito é forma de exercício do poder, pois "é uma maneira, na cultura ocidental, de, por meio da instituição judiciária, autenticar a verdade, revelar coisas que vão ser consideradas verdadeiras e transmiti-las." ${ }^{4}$

De acordo com Foucault, ${ }^{35}$ o discurso não é simplesmente aquilo que traduz as lutas ou os sistemas de dominação, mas é aquilo pelo qual e com o qual se luta, é o próprio poder de que procuramos assenhorear-nos. O autor afirma:

Cada sociedade define os tipos de discurso que ela recebe e põe a funcionar os mecanismos e as instâncias que permitirão que se diferenciem os enunciados verdadeiros dos falsos, as formas como se ratificam uns e outros; as técnicas e os procedimentos aos quais serão dados maior valor no alcance da verdade; a condição, o lugar que é conferido àqueles que se ocupam em dizer o que funciona como verdadeiro. ${ }^{36}$

Para ele, "o discurso nada mais é do que o reflexo de uma verdade que está sempre a nascer diante dos seus olhos." 37

De acordo com Bourdieu, é necessário que existam agentes para construir o discurso, instituições para validá-los e a aceitação da sociedade. ${ }^{38}$ Nota-se, assim, a importância e a complexidade do discurso. É importante, porque é um instrumento pelo qual são transmitidos valores e ideologias, e é complexo porque uma manifestação repleta de interesses de categorias e carregada de signos de poder. De acordo com Foucault, o discurso não deve ser compreendido apenas pelas palavras e pelas frases, porque o discurso é uma prática. Assim, ele afirma:

[...] o discurso não é uma estreita superfície de contato, ou de confronto, entre uma realidade e uma língua, o intrincamento entre um léxico e uma experiência [...] revela, afinal de contas, uma tarefa inteiramente diferente, que consiste em não mais tratar os discursos como conjuntos de signos [...] mas como práticas que formam sistematicamente os objetos de que falam. ${ }^{39}$ 
Laclau também compreende o discurso como um instrumento de linguagem que ultrapassa o campo meramente linguístico. $\mathrm{O}$ autor argumenta que o discurso é uma instância limítrofe com o campo social, "porque cada ato social tem um significado constituído na forma de sequencias discursivas que articulam elementos linguísticos e extralinguísticos." ${ }^{40}$ Assim, ele prossegue, "a sociedade poderia ser entendida como uma um vasto tecido argumentativo no qual a humanidade constrói a sua própria realidade." ${ }^{41}$

Nesse ponto, vale apresentar a análise de Brito a respeito do discurso jurídico. ${ }^{42} \mathrm{~A}$ autora aplicou as técnicas de análise de discurso para compreender e explicar os elementos que subsistem por trás do texto escrito das peças que compõem o processo judicial. Na linha de pensamento de Pêcheux, a análise do discurso enfoca a linguagem como prática social e busca investigar o modo como os indivíduos interagem pela linguagem e a descrição das funções que formas linguísticas realizam em práticas discursivas específicas, normalmente institucionais e ligadas ao Estado. ${ }^{43}$ Essa vertente dos estudos discursivos contempla a produção de sentido do discurso como resultante do processo de interação social. Dessa forma, busca compreender a relação entre o "eu" e o "outro".

Ao aplicar as técnicas de análise do discurso ao texto da denúncia, Brito observou que o promotor de justiça, assim se expressa: "O Representante do Ministério Público, ao final assinado, no uso de suas atribuições e na melhor forma de direito, vem, com base no incluso inquérito policial, oferecer denúncia contra: FULANO DE TAL, vulgo 'Zé ou Zé Maria' [...]." ${ }^{44}$ De acordo com as explicações de Brito, quando o promotor de justiça afirma serem "suas" as atribuições de denunciar os atos que não se enquadram nos moldes de uma sociedade equilibrada, coloca-se em uma posição de autoridade em relação àquele que está sendo por ele denunciado. No mesmo passo, quando afirma que o faz "na melhor forma de direito", está o representante do Ministério Público construindo a sua verdade única, irrefutável. Ao utilizar o termo "vulgo" para se referir ao denunciado, o sujeito se coloca em uma posição de superioridade, já que tal adjetivo coloca o "outro" na posição inferior de quem nem sequer é conhecido pelo próprio nome..$^{45}$

Em relação ao interlocutor do diálogo iniciado com o oferecimento da denúncia, que é o juiz, a análise de Brito confirma a ideia de que o texto acentua as relações de poder e força instauradas entre os sujeitos, pois apaga a voz do denunciado e ressalta a voz do juiz como o portador da verdade absoluta. De acordo com a análise da autora, o juiz recebe a denúncia, defere algumas diligências requeridas e decide: "[...] Entendo necessária a custódia cautelar do denunciado. Consoante podemos notar que o delito noticiado na peça acusatória se reveste de gravidade e gera indignação." ${ }^{46}$ Brito chama a atenção para o uso do verbo na $1^{a}$ pessoa, que expressa a posição de autoridade e poder. De acordo com Brito, o juiz faz uma recapitulação, apresentando os principais argumentos da acusação e da defesa e termina com as expressões "É o relatório", "Decido". Na sequência, ele apresenta os esclarecimentos sobre a teoria implícita, cita jurisprudências de outros tribunais e trechos da doutrina que 
servem para fortalecer seus argumentos e conclui: "Em face ao exposto e mais o que dos autos constam, o pedido contido na denúncia deve ser julgado PROCEDENTE". A seguir, ele aplica a pena e termina com as expressões costumeiras: "Publique-se", "Registre-se", "Intime-se", que, mais uma vez, denotam sua autoridade, definida no poder de falar por último e decidir o destino do réu. ${ }^{47}$

A partir das reflexões a respeito do discurso como uma expressão de poder, serão apresentadas, a seguir, situações extraídas dos autos processuais analisados para a presente pesquisa. Buscou-se, sempre que possível, interpretar tais situações à luz das reflexões de Bourdieu concernentes ao Direito como um poder simbólico e de algumas abordagens sobre os meios de vida.

\section{O PODER SIMBÓLICO DO DIREITO E OS REFLEXOS SOBRE OS MEIOS DE VIDA DOS AGRICULTORES FAMILIARES}

Tendo em vista as interferências da legislação ambiental sobre os meios de vida dos agricultores familiares, a penalidade apresenta-se como um dos aspectos mais relevantes, visto que todo o conjunto de acontecimentos que o agricultor passa a vivenciar, a partir do momento em que recebe uma autuação, reflete-se em sua forma de vida, tanto do ponto de vista material e social quanto do psicológico.

Em geral, diante de uma infração ambiental, a primeira penalidade aplicada é a multa administrativa. Na maior parte dos casos analisados, o valor a pagar ficou entre $\mathrm{R} \$ 1.000,00 \mathrm{e}$ $\mathrm{R} \$ 2.000,00$, de acordo com o tipo de infração praticado. Os parâmetros para a determinação do valor da multa estão estabelecidos em decreto. Os policiais ambientais entrevistados teceram críticas a tais parâmetros, porque, de acordo com eles, provocam situações de disparidade. Disse o sargento comandante da equipe: "uma intervenção em área de até um hectare gera uma multa de mil e trezentos reais. Se for um centésimo de hectare ou um hectare, a multa é a mesma. Esse valor às vezes é muito baixo para uns e muito alto para outros." 48

Com frequência, os agricultores mencionaram que quem tem poder econômico consegue livrar-se do problema, e quem não tem é penalizado.

A influência do poder econômico do infrator não passa despercebida para o promotor de justiça da Comarca que, em entrevista, afirmou que a maior parte das pessoas autuadas são pobres e que "[...] não se sabe se há uma predileção da polícia por esse público ou se existe um receio de atuação quando o poder econômico é expressivo.”

A fala do promotor reflete um modelo de sociedade hierarquizada, segundo o qual até mesmo as instituições atuam de forma preconceituosa em relação aos sujeitos periféricos. Cabe mencionar Souza e a ideia da tríade meritocrática, que envolve qualificação, posição e salário, três características que, de acordo com esse autor, definem o status do indivíduo na sociedade. ${ }^{49}$ 
Em geral, quem possui qualificação, posição e salário possui, também, o capital social, que, de acordo com Bourdieu, constitui um ativo individual que determina as diferenças de vantagens extraídas do capital econômico que um indivíduo possui, adquirido por meio das redes de conhecimentos, de influências que ele estabelece ao longo de sua vida. ${ }^{50}$ Ainda conforme Bourdieu, um mínimo de capital econômico é fundamental para que o indivíduo consiga inserir-se em um grupo; e, uma vez que isto ocorra, cria-se um círculo de relacionamentos, relativamente independente do capital econômico. ${ }^{51} \mathrm{O}$ capital social, assim, é capaz de ampliar as oportunidades do indivíduo porque facilita sua inserção nas altas camadas de poder político, econômico e social. De acordo com Bebbington, o acesso pode ser visto como analiticamente anterior à constituição da plataforma de ativos, pois acesso a outros atores precede o acesso a recursos. ${ }^{52}$

Bourdieu esclarece que "as condutas dos agentes jurídicos podem sujeitar-se mais ou menos às exigências da lei dependendo da composição do grupo de decisão ou dos atributos dos que estão sujeitos à jurisdição." ${ }^{53} \mathrm{O}$ autor afirma que a prática dos agentes encarregados de produzir o Direito ou de aplicá-lo deve muito às finalidades que unem os detentores do poder simbólico aos detentores do poder temporal, político ou econômico. Nesse sentido, o Direito pode ser um instrumento útil para oprimir os grupos dominados, visto que grupos mais vulneráveis, portanto, dominados, serão investigados, inquiridos, e/ou processados por grupos mais fortes, portanto, dominantes, neste trabalho, exemplificados por polícia, promotores, juízes.

Continuando as observações a respeito dos processos analisados, foi possível perceber que a realização de TACs tem sido a principal solução utilizada para resolver os casos de degradação ambiental e de desenvolvimento de atividades irregulares. Quando realizado o acordo, é comum o Ministério Público solicitar a apresentação de um projeto técnico de reconstituição da flora (PTRF), além de determinar a aquisição e o plantio de mudas. Aceita a proposta, é concedido um prazo para que a regeneração da área ocorra, e, durante esse período, o autuado deverá comparecer mensalmente ao fórum para prestar contas. $\mathrm{O}$ custo do PTRF, de acordo com os dados constantes nos processos, inicia-se em $\mathrm{R} \$ 1.500,00$, na modalidade mais simplificada, podendo chegar a valores bem maiores, dependendo da situação do local e das exigências da justiça.

Para que a justiça possa determinar as medidas de reparação e/ou compensação do dano ambiental, é necessário que exista um laudo atestando a existência e a extensão desse dano. Esse laudo é realizado por órgão estadual ou por profissional particular habilitado, desde que custeada pelo agente causador do dano. Nesse último caso, o infrator arcará, portanto, com dois pagamentos no valor de $\mathrm{R} \$ 272,00$, um no começo do processo para constatar o dano, e outro, ao final, para averiguar o cumprimento das obrigações assumidas.

Muitos dos TACs analisados tiveram de ser executados porque, embora tenham sido aceitos, a pessoa infringente não conseguiu cumprir o seu. Acredita-se que a pessoa aceita 
a proposta por se sentir intimidada diante do cenário forense, mas, na verdade, pouco compreende acerca do que está sendo proposto, mesmo porque, na maioria dos casos, não está acompanhada de advogado.

Embora o TAC seja apresentado como uma forma mais célere de resolução do problema, porque evita o embate judicial que pressupõe produção de provas, não significa que, a partir de então, a questão será encerrada. Durante o período de cumprimento do ajuste, deve haver o comparecimento mensal à sede do Ministério Público para prestação de contas. Os agricultores que passaram por essa experiência enfatizaram que o fato de terem de comparecer ao fórum comprometia o trabalho na propriedade, pois representava perda de dia de serviço, em um contexto em que a mão de obra é escassa e a direção dos trabalhos corre por conta apenas do dono da terra: "mão de obra é muito difícil de achar [...] É a gente mesmo [...] Se sair, perde o dia [...]."

Se, além de dano ambiental, o fato configurar crime ambiental, será lavrado um Termo Circunstanciado de Ocorrência que será encaminhado ao Juizado Especial Criminal. Se o crime apresentar pena máxima superior a dois anos, o fato deverá ser investigado por meio de inquérito, que será encaminhado para a Justiça Comum. Durante a pesquisa realizada na Comarca de Viçosa, foram constatados apenas dois processos em curso na Justiça Comum, no período em estudo. Os demais casos tramitam no Juizado Especial Criminal.

A maior parte dos processos em trâmite no Juizado Especial foi solucionada por meio da transação penal que se concretizou em uma multa no valor de um salário-mínimo, cujo pagamento, em geral, foi feito de modo parcelado. A determinação, geralmente, é para que o valor seja depositado em uma conta do Tribunal de Justiça ou na conta do Fundo Nacional do Meio Ambiente, mas foram constatados muitos casos em que a determinação era para que o agente depositasse o dinheiro na conta bancária de alguma instituição beneficente municipal, como Mobilização Educativa Maria da Conceição Batalha, Associação Protetora de Animais ou Associação São Vicente de Paula. De acordo com determinação da lei de crimes ambientais, os valores arrecadados devem ser destinados ao Fundo Nacional do Meio Ambiente para reparar o dano onde houve o impacto. Entretanto, como não foi instituída forma de controle para esse procedimento, nem sempre ele é cumprido.

Nos casos em que o agente tenha sido beneficiado pela transação penal há menos de cinco anos, ou tenha sido condenado à pena privativa de liberdade, não é possível a proposição de novo acordo; a condenação, então, costuma ser a uma pena de detenção, de seis meses a um ano. De acordo com o artigo 60, § 2º do Código Penal, ${ }^{54}$ cabe ao Estado, ao aplicar a pena de detenção, apresentar a opção de substituição desta por uma pena pecuniária. Nos casos analisados, tais penas foram substituídas por prestações pecuniárias a entidades beneficentes, em valores que variavam de $\mathrm{R} \$ 1.000,00$ a $\mathrm{R} \$ 2.000,00$, sempre parceladas.

A partir da leitura e da análise realizadas, foi possível observar que, na primeira instância, os processos, com frequência, seguem o rito de forma bastante padronizada; embora, algumas vezes, os fatos sejam diferentes, a modalidade e a duração da pena são as mesmas. Em alguns 
casos, foi possível notar algumas disparidades em relação ao valor da multa aplicada. Foram observadas situações em que o juiz aplicou pena de multa de um salário mínimo em razão do desmate de 0,15 hectares de terra. Em outro processo, aplicou a mesma pena em razão de desmate de um hectare de terra. E em outro, ainda, aplicou a mesma pena de um salário mínimo a um indivíduo que havia vendido 16 pássaros silvestres. A respeito desse último caso, que não se trata de um agricultor familiar, o infrator estava respondendo ao sexto processo por venda de pássaros silvestres e, em todos os casos, as penas por ele recebidas eram inferiores ao valor recebido pela venda de cada pássaro.

Quanto à característica de a maior parte dos crimes previstos na Lei de Crimes Ambientais contar com penas máximas inferiores a dois anos e, portanto, serem processados no Juizado Especial Criminal, compreende-se que seja uma escolha do legislador coerente com os interesses que havia por trás da criação dessa lei. Entretanto, a aplicação mecânica de penas mínimas aos diversos tipos de infração reflete uma despreocupação com a função social da pena, pois um agricultor que cortou árvores para fazer cerca recebeu a mesma pena que um infrator reincidente na venda de pássaros silvestres. A ideia que transparece é a de que o Direito foi brando para o criminoso e árduo para o trabalhador. Além disso, para o infrator que vendia pássaros, funcionou como um incentivo, pois a pena foi bem menor do que o benefício auferido, e ainda foi parcelada. Tanto que esse infrator já estava respondendo ao sexto processo pela mesma prática.

A esse respeito, vale mencionar a ideia de Dworkin, que propõe interpretar a prática jurídica como uma atividade dinâmica que compreenda o Direito como um processo em desenvolvimento contínuo. Essa ideia nega o traço convencionalista de Direito unicamente como relato de fatos estabelecidos no passado e propõe uma atividade interpretativa que combine tanto elementos voltados para o passado quanto para o futuro. ${ }^{55}$

Em relação aos acórdãos do Tribunal de Justiça de MG (TJMG) que foram analisados, não se observou a mesma linha padronizada das decisões. Quanto à venda de pássaros silvestres, o TJMG tem se posicionado favoravelmente à condenação aplicada pelos juízes de primeira instância, inclusive com reconhecimento de causas de aumento de pena. Já em relação aos desmates realizados por agricultores familiares, há decisões do TJMG compreendendo que não existe adequação social em punir pessoas que provocam danos ambientais mínimos na busca pela subsistência. Dessa forma, não manteve a decisão de primeira instância e absolveu o acusado.

Considerando a área mínima desmatada; considerando a situação real da acusada; considerando a necessidade induvidosa de ter-se a subsistência familiar como valor superior ao bem atingido que, aliás, é passível de recomposição, conforme laudo do IEF, f. 13/14, não se mostra socialmente adequada uma punição criminal a quem, como visto, já é punida pela própria carência a que está submetida, juntamente com sua família. ${ }^{56}$ 
Apesar de as instâncias superiores apresentarem uma visão mais moderada da situação e considerarem o contexto social das partes envolvidas para a elaboração da decisão, poucos processos chegam a ser analisados pelo tribunal, visto que razões diversas, como a baixa renda e o baixo grau de instrução, fazem com que dificilmente a questão chegue até as instâncias recursais. Da sentença que homologa o acordo de transação penal cabe um único recurso, que é a apelação, mas também esse é muito pouco utilizado, mesmo porque, por ser a transação penal uma espécie de acordo, pressupõe-se que os dois lados estejam cientes e dispostos a cumprir o combinado.

baixo quantitativo de infrações ambientais praticadas por agricultores que chega ao conhecimento dos tribunais demonstra que esse grupo possui uma dificuldade de acessar as instâncias superiores, até porque isso não é possível sem a presença de um advogado/ defensor. Sobre esse aspecto, vale mencionar Niederle e Grisa, de acordo com os quais o conjunto de ativos (na pesquisa aqui relatada, o acesso tem sido compreendido como um ativo) constitui a base de poder dos atores, pois é o que permite a eles se reproduzirem e alterarem as estruturas institucionais sob as quais a reprodução ocorre. ${ }^{57}$ Nessa perspectiva, possibilitar acesso aos ativos torna-se uma política de empoderamento, uma vez que afeta as relações de poder que geralmente dificultam aos indivíduos e grupos construírem suas estratégias para garantir a vida.

Sobre a divergência de opiniões entre os juízes de primeira instância e os desembargadores do tribunal, Bourdieu afirma que todo campo pode ser dividido em regiões menores, os subcampos. ${ }^{58}$ Nesse sentido, as instâncias judiciais (inferiores e superiores) podem ser consideradas subcampos do campo do direito. Nesses subcampos, as frações sociais dominantes impõem a sua espécie de capital como princípio de hierarquização do campo. Não se trata de uma luta meramente política, mas de uma luta, na maioria das vezes inconsciente, pelo poder. Por esse raciocínio, ao reformar as decisões de primeira instância e apresentar pareceres mais elaborados e atualizados de acordo com as discussões contemporâneas, as instâncias superiores estariam firmando o seu poder perante as instâncias jurídicas inferiores.

De acordo com Bourdieu, aqueles que compõem o campo jurídico concorrem pelo monopólio do direito de "dizer o direito", ou seja, de apresentar a interpretação definitiva do fato à luz do direito, o veredito. 59 "São agentes investidos de competência ao mesmo tempo social e técnica que consiste essencialmente na capacidade reconhecida de interpretar um texto que consagra a visão legítima, justa, do mundo social." ${ }^{60}$ Assim, Bourdieu ressalta que eles próprios se dividem em grupos com interesses divergentes e, até mesmo opostos, em função da posição na hierarquia interna. ${ }^{61}$

A partir das leituras processuais, apresentam-se, também, aqui, algumas considerações a respeito da lei de crimes ambientais, que parecem importantes. A primeira observação dá conta de que existe uma dependência da lei ambiental em relação ao Direito Administrativo. Em muitos casos, a lei ambiental necessita se valer do Direito Administrativo para definir 
o tipo penal. Essa característica tem sido denominada pela doutrina como "acessoriedade administrativa." ${ }^{2}$ Assim, muitos tipos penais descritos necessitam de complementação dada por portarias ou resoluções. Além disso, grande parte das ações tipificadas como crime ambiental descreve um fato em que o agente praticou uma conduta, sem a autorização ou a permissão do órgão ambiental competente. Assim, o que caracteriza o crime é a falta da autorização administrativa.

Reconhece-se a importância da regulamentação administrativa no caso dos crimes ambientais, pois tais normas abordam temas específicos, por exemplo, níveis de poluição, o que talvez seja difícil de ser previsto no texto da lei. Mas acredita-se que mais importante do que averiguar se existe a autorização do órgão competente é averiguar se, de fato, ocorreu o dano ambiental e, ainda, se houve dolo/culpa na conduta do agente. Em muitos processos analisados, não foi possível constatar o dolo do agricultor, nem mesmo o dano, pois, em razão da demora na realização das perícias, muitas vezes, a própria natureza se encarrega da recomposição do ambiente.

Outro aspecto que pode ser pontuado se refere ao fato de os atos administrativos poderem ser modificados de forma mais fácil do que as leis. E, se grande parte da legislação destinada a coibir crimes ambientais vincula-se a definições e especificações constantes em atos administrativos, aquela também se torna facilmente mutável, o que comprometeria a segurança jurídica dos destinatários. ${ }^{63}$ Além disso, ainda existe o risco de criminalizar meras desobediências administrativas, que podem não acarretar dano ou risco de dano ao bem jurídico tutelado que é o meio ambiente. Assim, pune-se a falta de permissão ou autorização e não o prejuízo ambiental que a conduta poderia causar, pois esse não é avaliado. ${ }^{64}$ Por fim, tal prática pode abrir margem para o arbítrio da autoridade administrativa responsável pela fiscalização. ${ }^{65}$

Compreende-se que essa vinculação entre a legislação ambiental e o Direito Administrativo seja um aspecto que dificulta bastante o cumprimento da norma, pois a prática da conduta correta depende, em certa medida, de alguma instrução ou assessoria, e, muitas vezes, também, do pagamento de taxas. Mais uma vez, portanto, volta-se à questão do acesso. De acordo com Bebbington, frequentemente, o acesso constitui o recurso mais crítico. Melhorar o acesso a ativos remete ao desenvolvimento tanto de capacidades individuais e coletivas quanto das estruturas de oportunidade (contexto social, político e econômico) que constrangem ou facilitam o acesso. ${ }^{66}$

Com relação às funções da pena, cabe mencionar que, de forma geral, são duas as funções básicas: a repressão ao crime perpetrado e a prevenção de novos delitos. Portanto, os seus principais objetivos são reeducar o infrator e intimidar a sociedade para que o crime seja evitado. Pelas razões expostas anteriormente, acredita-se que, da forma como o Estado tem tratado a questão ambiental, ele não tem conseguido reeducar os que agem trazendo prejuízo ao meio ambiente e, também, não tem coibido a ação criminosa. Apesar de haver 
uma legislação considerada moderna e uma doutrina ampla sobre o tema, a aplicação do direito no que se refere às questões ambientais reafirma uma justiça lenta, burocrática e, muitas vezes, desigual, o que amplia o descrédito da sociedade em relação ao Estado e às instituições.

As entrevistas evidenciaram esse aspecto, na medida em que permitiram ouvir, de quem figurou ou figura na condição de réu, não apenas aquilo que já se esperava a respeito de custos, aborrecimentos, tratamento desigual, mas também relativamente à falta de confiança nas autoridades, nas instituições e no Estado. Os entrevistados não se posicionaram contra a lei; mas se manifestaram contra quem faz a lei e contra quem a aplica. Isto demonstra que as experiências dessas pessoas com relação à justiça deixaram o sentimento de decepção, de desconfiança e de desamparo. De acordo com Bourdieu, "a eficácia do direito surge na medida em que ele é socialmente reconhecido e se depara com um acordo, mesmo tácito e parcial, de resposta às necessidades e interesses reais." 67

Ainda conforme Bourdieu, enquanto pertencente à ordem da ideologia ou dos sistemas simbólicos, o Direito não faz senão consagrar simbolicamente o estado da correlação de forças entre os grupos. $\mathrm{O}$ autor esclarece, entretanto, que "a eficácia simbólica do direito acontece menos por intenções conscientes e mais pelos mecanismos estruturais." ${ }^{68} \mathrm{O}$ que ocorre é que os detentores de posições dominantes no campo jurídico, como policiais, promotores e juízes, tendem a ser mais favoráveis à clientela dos dominantes e isso aumenta, ainda mais, a inferioridade dos dominados, no caso em tela, os agricultores familiares. E assim, Bourdieu conclui que "o campo jurídico consagra o esforço dos grupos dominantes para imporem uma representação oficial do mundo social que esteja de acordo com seus interesses." 69

A convergência das posições tomadas pelo Judiciário com os interesses dos grupos economicamente mais fortes decorre, segundo Bourdieu, ${ }^{70}$ da proximidade de habitus daqueles que compõem o Poder Judiciário com aqueles que representam o grupo dos dominantes, devido a formações familiares e escolares que receberam. Assim, de acordo com o autor, "há poucas probabilidades de as decisões judiciais desfavorecerem os dominantes. A própria lógica dos textos jurídicos, repletos de lacunas e ambiguidades, estão adequados aos interesses e valores dos dominantes."71

Desse modo, Bourdieu, na obra acima citada, conclui que o Direito é uma forma de poder simbólico. No mesmo sentido, vale lembrar, aqui, um juiz americano, mencionado por Dworkin, na obra "O império do Direito", que dizia ter mais medo de um processo judicial do que da pena de morte ou dos impostos a serem pagos, isto porque, os processos judiciais, dizia esse juiz, têm, às vezes, consequências muito amplas e imprevisíveis.

Não à toa os símbolos do Direito (espada, martelo, balança, toga, pena) estão ligados à ideia de força, pois o poder que nele reside de fato é capaz de trazer para o cidadão o sentimento de temor. Por meio do veredito (do latim: verdadeiramente dito), o Direito classifica e define a pessoa, pois ele representa "a palavra autorizada, a palavra pública, 
oficial, enunciada em nome de todos e perante todos por mandatários autorizados de uma coletividade." ${ }^{2}$ Por meio da decisão judicial, o indivíduo é classificado perante a sociedade como honesto, criminoso, bom/mau caráter.

As consultas e análises processuais e, principalmente, as entrevistas realizadas com os agricultores evidenciaram a condição desses sujeitos como súditos do Direito. À luz da literatura dos meios de vida, foi possível perceber que a lei interfere, de maneiras diversas, na forma de as pessoas ganharem a vida, mas as principais interferências por ela produzidas não se referem ao aspecto econômico, mas aos acessos, seja às instâncias públicas, às concessões da lei ou aos órgãos que poderiam ajudá-los. Falta capital econômico e, consequentemente, capital social que possa lhes auxiliar, nesses espaços, a exercerem os direitos que, muitas vezes, a lei lhes concede, mas que ficam apenas no papel.

De acordo com Niederle e Grisa, ${ }^{73} \mathrm{O}$ acesso envolve, basicamente, as esferas do mercado, do Estado e da sociedade civil em suas diferentes escalas. Cada uma dessas esferas sociais possui sua própria lógica de ação, exigindo determinados comportamentos dos agentes e influenciando, ao seu modo, a distribuição, o controle e a transformação dos ativos. ${ }^{74}$ Conforme Bebbington, as dificuldades de democratização do acesso decorrem, principalmente, do fato de que as pessoas com maior dotação inicial de ativos dominam os recursos, uma vez que conseguem constituir relações mais próximas aos atores do mercado, do Estado e da sociedade civil. Pessoas com menores dotações apresentam capacidade limitada para construir redes que poderiam intermediar o acesso. ${ }^{75}$

Desse modo, uma questão essencial passa a ser compreender como as pessoas com menos dotações podem desenvolver o acesso a atores e ativos; ou seja, quais são as formas de construir acessos? Por meio das entrevistas, foi possível notar que existe muita disposição, por parte dos agricultores e de seus familiares, para buscar formas de superar os obstáculos. O entusiasmo dos proprietários em reafirmar o desejo de permanecer no campo e de permanecer na luta por melhores condições vai ao encontro do viés otimista da abordagem dos meios de vida, de acordo com o qual as dificuldades conduzem à criação de novas estratégias de sobrevivência.

\section{CONCLUSÕES}

Por meio desta pesquisa, foi possível constatar que grande parte dos agricultores familiares da região estudada faz uso indevido da terra, e isso os coloca em situação vulnerável porque ficam sujeitos a uma autuação e, até mesmo, a um processo judicial, o que pode trazer consequências que vão muito além do custo monetário ou do desgaste pessoal.

Embora o Poder Judiciário, com frequência, utilize mecanismos extrajudiciais para solução de tais problemas, como é o caso dos TACs (Termos de Ajustamento de Conduta), a posição de desvantagem dos agricultores em face do poder do Estado foi evidenciada pela 
incapacidade de tais sujeitos utilizarem os mecanismos legais de defesa, como a defesa técnica realizada por advogado ou mesmo o acesso aos recursos. Ficou evidenciado, portanto, que a lei é elemento constitutivo dos meios de vida porque, à medida que se apresenta como "geral e abstrata", "igual para todos", promove efeitos mais gravosos sobre aqueles que não possuem os acessos e as redes de relacionamento eficazes para lhes garantir imunidade. Nesse sentido, a lei funciona como um elemento de poder e, como tal, em lugar de promover o tratamento equânime entre os diversos grupos sociais, amplia e reforça o histórico de exclusão, já existente nas esferas social e econômica.

As consultas processuais realizadas mostraram que a exclusão social e econômica que marca a história da sociedade brasileira se reflete no campo jurídico, pois os grupos social e economicamente mais fortes encontram mais facilidade para se adequarem às exigências legais e, assim, escaparem das punições, enquanto os grupos mais vulneráveis enfrentam maiores dificuldades tanto para cumprir as obrigações legais, quanto para se defenderem das acusações e mostrarem suas limitações.

Constatou-se, ainda, que as decisões judiciais são bastante padronizadas e até mesmo o valor das multas estabelecidas nas transações penais costumam ter o mesmo valor, embora as infrações sejam diferentes. Apesar de a lei e o próprio Judiciário reconhecerem a condição de vulnerabilidade do agricultor, não existem medidas no sentido de corrigir o desnível, como a estruturação de órgãos (inclusive voluntários) que possam prestar assistência e oferecer apoio para viabilizar a defesa dos agricultores ou torná-la mais eficiente. Assim, as garantias constitucionais e legais, como o acesso aos recursos ou o direito de ser tratado com dignidade ou de receber uma pena proporcional à gravidade da conduta praticada, acabam ficando apenas no papel.

\section{REFERÊNCIAS}

BARROSO, Luís Roberto. Grandes transformações do direito contemporâneo e o pensamento de Robert Alexy. In: ALEXY, Robert et al. Princípios formais e outros aspectos da teoria discursiva do direito. Rio de Janeiro: Forense Universitária, 2014. p. 69-99. Disponível em: <http://s.conjur.com.br/dl/palestra-barroso-alexy.pdf>. Acesso em: nov. 2014.

BEBBINGTON, Anthony. Capitals and capabilities: a framework for analyzing peasant viability, rural livelihoods and poverty. World Development, United Kingdom, v. 27, n. 12, p. 2021-2044, 1999.

BOURDIEU, Pierre. Questões de sociologia. Tradução Jeni Vaitsman. Rio de Janeiro: Marco Zero, 1984.

. Coisas ditas. Tradução Cássia R. da Silveira e Denise Moreno Pegorim. São Paulo: Brasiliense, 1987. 
. O poder simbólico. Tradução Fernando Tomaz. 6. ed. Rio de Janeiro: Bertrand Brasil, 2003.

BRASIL. Constituição (1988). Constituição da República Federativa do Brasil, de 5 de outubro de 1988. Brasília, DF, 05 out. 1988. Presidência da República, Brasília, DF. Disponível em: <http://www.planalto.gov.br/ccivil_03/Constituicao/Constituiçao.htm>. Acesso em: 2 abr. 2013.

BRASIL. Decreto-lei no 2.848, de 7 de dezembro de 1940. Código Penal. Diário Oficial da União (DOU), Rio de Janeiro, Seç. 1, p. 23911, 31 dez. 1940. (Publicação Original). Disponível em: <http://www.planalto.gov.br/ccivil_03/decreto-lei/Del2848compilado.htm>. Acesso em: 14 maio 2015.

BRASIL. Tribunal de Justiça do Estado de Minas Gerais. Inteiro teor dos acórdãos: leis especiais. Disponível em: <http://www.tjmg.jus.br $>$.

BRITO, Diná T. de. Linguagem: o poder no discurso jurídico. Diálogo e Interação, Paraná, v. 1, 2009. Disponível em: <http://www.faccrei.edu.br/gc/anexos/diartigos14.pdf $>$. Acesso em: maio 2016.

COSTA, Helena Regina Lobo da. Os crimes ambientais e sua relação com o direito administrativo. In: VILARDI, Celso S.; BRESSER-PEREIRA, Flávia R.; DIAS NETO, Theodomiro. Direito penal econômico: análise contemporânea. São Paulo: Saraiva, 2009. p. 189-222.

DERRIDA, Jacques. Força de lei: o fundamento místico da autoridade. Tradução Leyla Perrone-Moisés. São Paulo: Martins Fortes, 2007.

DWORKIN, Ronald. O império do direito. Tradução Jefferson Luiz Camargo. São Paulo: Martins Fontes, 2003.

FOUCAULT, Michel. A verdade e as formas jurídicas. 3. ed. Tradução Roberto C. de M. Machado e Eduardo J. Morais. Rio de Janeiro: Nau, 2002.

. A ordem do discurso: aula inaugural no Collège de France, em 2 de dezembro de 1970. 16. ed. Tradução Laura F. de A. Sampaio. São Paulo: Loyola, 2008.

. História da loucura na Idade Clássica. 8. ed. Tradução José Teixeira Coelho Netto. São Paulo: Perspectiva, 2008.

. O sujeito e o poder. In: DREYFUS, Hubert L.; RABINOW, Paul. Michel Foucault, uma trajetória filosófica: para além do estruturalismo e da hermenêutica. Tradução Vera Porto Carrero. Rio de Janeiro: Forense Universitária, 1995.

LACLAU, Ernesto. A política e os limites da modernidade. In: HOLLANDA, Heloísa B. Pós-modernismo e política. Rio de Janeiro: Rocco, 1991. p. 127-150.

LAKATOS, Eva Maria; MARCONI, Marina de Andrade. Fundamentos de metodologia científica. 5. ed. São Paulo: Atlas, 2003. 
MEURER, José Luiz. Aspectos do processo de produção de textos escritos. Trab. de Ling. Apl., Campinas, v. 21, p. 49-62, jan./jun. 1993. Disponível em: < http://revistas.iel.unicamp. br/index.php/tla/article/view/2632/2042>. Acesso em: maio 2013.

MINAS GERAIS (Estado). Decreto ${ }^{\circ} \mathbf{4 4 . 8 4 4 , ~ d e ~} 25$ de junho de 2008. Estabelece normas para licenciamento ambiental e autorização ambiental de funcionamento, tipifica e classifica infrações às normas de proteção ao meio ambiente e aos recursos hídricos e estabelece procedimentos administrativos de fiscalização e aplicação das penalidades. Disponível em: <http://www.siam.mg.gov.br/sla/download.pdf?idNorma=7966>. Acesso em: jan. 2013.

NIEDERLE, Paulo André; GRISA, Catia. Diversificação dos meios de vida e acesso a atores e ativos: uma abordagem sobre a dinâmica de desenvolvimento local da agricultura familiar. Cuadernos de Desarrollo Rural, v. 5, n. 61, p. 41-69, 2008. Disponible en: <http://www. redalyc.org/articulo.oa?id=11713138002 > . Acesso em: 16 maio 2016.

PÊCHEUX, Michel. Semântica e discurso: uma crítica à afirmação do óbvio. Tradução Eni P. de Orlandi et alii. Campinas: Editora da UNICAMP, 1988.

RINALDI, Alessandra de Andrade. Sexualização do crime no Brasil: um estudo sobre criminalidade feminina no contexto das relações amorosas (1890-1940). Rio de Janeiro: Mauad X: Faperj, 2015.

SANTOS, Boaventura de Sousa. O discurso e o poder: ensaio sobre a sociologia da retórica jurídica. Porto Alegre: Fabris, 1988.

SOUZA, Jessé. A construção social da subcidadania: para uma sociologia política da modernidade periférica. Belo Horizonte: Editora da UFMG, 2006.

VIANNA, Adriana de Resende Barreto. Limites da menoridade: tutela, família e autoridade em julgamento. 2002. 350f. Tese (Doutorado em Antropologia Social) - Universidade Federal do Rio de Janeiro (UFRJ), Rio de Janeiro, 2002.

WOORTMANN, Klaas. Com parente não se neguceia: o campesinato como ordem moral. Anuário Antropológico, Brasília, v. 87, p. 11-73, 1990.

1 LAKATOS, Eva Maria; MARCONI, Marina de Andrade. Fundamentos de metodologia científica. 5. ed. São Paulo: Atlas, 2003.

2 MINAS GERAIS (Estado). Decreto $\mathrm{n}^{\circ}$ 44.844, de 25 de junho de 2008. Estabelece normas para licenciamento ambiental e autorização ambiental de funcionamento, tipifica e classifica infrações às normas de proteção ao meio ambiente e aos recursos hídricos e estabelece procedimentos administrativos de fiscalização e aplicação das penalidades. Disponível em: <http://www.siam.mg.gov.br/sla/download.pdf?idNorma=7966>. Acesso em: jan. 2013.

3 A lei admite que a multa seja parcelada em até sessenta parcelas mensais, observados os requisitos legais.

4 WOORTMANN, Klaas. Com parente não se neguceia: o campesinato como ordem moral. Anuário Antropológico, Brasília, v. 87, p. 11-73, 1990.

5 BOURDIEU, Pierre. O poder simbólico. Tradução Fernando Tomaz. 6. ed. Rio de Janeiro: Bertrand Brasil, 2003.

6 BOURDIEU, Pierre. Coisas ditas. Tradução Cássia R. da Silveira e Denise Moreno Pegorim. São Paulo: Brasiliense, 1987. p. 22. 
7 BOURDIEU, Pierre. Questões de sociologia. Tradução Jeni Vaitsman. Rio de Janeiro: Marco Zero, 1984. p. 119.

8 Idem.

9 BOURDIEU, Pierre. Questões de sociologia. Tradução Jeni Vaitsman. Rio de Janeiro: Marco Zero, 1984.

10 BOURDIEU, Pierre. O poder simbólico. Tradução Fernando Tomaz. 6. ed. Rio de Janeiro: Bertrand Brasil, 2003. p. 8.

11 Idem, p. 11.

12 Idem, op. cit.

13 SANTOS, Boaventura de Sousa. O discurso e o poder: ensaio sobre a sociologia da retórica jurídica. Porto Alegre: Fabris, 1988. p. 230.

14 BOURDIEU, Pierre. O poder simbólico. Tradução Fernando Tomaz. 6. ed. Rio de Janeiro: Bertrand Brasil, 2003.

15 DWORKIN, Ronald. O império do direito. Tradução Jefferson Luiz Camargo. São Paulo: Martins Fontes, 2003. p. 254.

16 DWORKIN, Ronald. O império do direito. Tradução Jefferson Luiz Camargo. São Paulo: Martins Fontes, 2003. p. 255.

17 DERRIDA, Jacques. Força de lei: o fundamento místico da autoridade. Tradução Leyla Perrone-Moisés. São Paulo: Martins Fortes, 2007. p. 44.

18 BARROSO, Luís Roberto. Grandes transformações do direito contemporâneo e o pensamento de Robert Alexy. In: ALEXY, Robert et al. Princípios formais e outros aspectos da teoria discursiva do direito. Rio de Janeiro: Forense Universitária, 2014. p. 69-99. Disponível em: <http://s.conjur.com.br/dl/palestra-barroso-alexy.pdf>. Acesso em: nov. 2014.

19 BOURDIEU, Pierre. O poder simbólico. Tradução Fernando Tomaz. 6. ed. Rio de Janeiro: Bertrand Brasil, 2003.

20 MEURER, José Luiz. Aspectos do processo de produção de textos escritos. Trab. de Ling. Apl., Campinas, v. 21, p. 49-62, jan./jun. 1993. Disponível em: http://revistas.iel.unicamp.br/index.php/tla/article/view/2632/2042 >. Acesso em: maio 2013.

21 FOUCAULT, Michel. O sujeito e o poder. In: DREYFUS, Hubert L.; RABINOW, Paul. Michel Foucault, uma trajetória filosófica: para além do estruturalismo e da hermenêutica. Tradução Vera Porto Carrero. Rio de Janeiro: Forense Universitária, 1995.

22 FOUCAULT, Michel. A verdade e as formas jurídicas. 3. ed. Tradução Roberto C. de M. Machado e Eduardo J. Morais. Rio de Janeiro: Nau, 2002.

23 Idem.

24 FOUCAULT, Michel. O sujeito e o poder. In: DREYFUS, Hubert L.; RABINOW, Paul. Michel Foucault, uma trajetória filosófica: para além do estruturalismo e da hermenêutica. Tradução Vera Porto Carrero. Rio de Janeiro: Forense Universitária, 1995.

25 BOURDIEU, Pierre. O poder simbólico. Tradução Fernando Tomaz. 6. ed. Rio de Janeiro: Bertrand Brasil, 2003. p. 237.

26 BRASIL. Constituição (1988). Constituição da República Federativa do Brasil, de 5 de outubro de 1988. Brasília, DF, 05 out. 1988. Presidência da República, Brasília, DF. Disponível em: <http://www.planalto.gov.br/ccivil_03/ Constituicao/Constituiçao.htm>. Acesso em: 2 abr. 2013.

27 FOUCAULT, Michel. História da loucura na Idade Clássica. 8. ed. Tradução José Teixeira Coelho Netto. São Paulo: Perspectiva, 2008.

28 VIANNA, Adriana de Resende Barreto. Limites da menoridade: tutela, família e autoridade em julgamento. 2002. 350f. Tese (Doutorado em Antropologia Social) - Universidade Federal do Rio de Janeiro (UFRJ), Rio de Janeiro, 2002. p. 94.

29 Idem.

30 RINALDI, Alessandra de Andrade. Sexualização do crime no Brasil: um estudo sobre criminalidade feminina no contexto das relações amorosas (1890-1940). Rio de Janeiro: Mauad X: Faperj, 2015. p. 29.

31 FOUCAULT, Michel. A verdade e as formas jurídicas. 3. ed. Tradução Roberto C. de M. Machado e Eduardo J. Morais. Rio de Janeiro: Nau, 2002.

32 Idem.

33 BOURDIEU, Pierre. O poder simbólico. Tradução Fernando Tomaz. 6. ed. Rio de Janeiro: Bertrand Brasil, 2003.

34 FOUCAULT, Michel. A ordem do discurso: aula inaugural no Collège de France, em 2 de dezembro de 1970. 16. ed. Tradução Laura F. de A. Sampaio. São Paulo: Loyola, 2008. p. 77-78. 
35 FOUCAULT, Michel. A ordem do discurso: aula inaugural no Collège de France, em 2 de dezembro de 1970. 16. ed. Tradução Laura F. de A. Sampaio. São Paulo: Loyola, 2008.

36 Ibid, p. 12.

37 Ibid, p. 13.

38 BOURDIEU, Pierre. O poder simbólico. Tradução Fernando Tomaz. 6. ed. Rio de Janeiro: Bertrand Brasil, 2003.

39 A ordem do discurso: aula inaugural no Collège de France, em 2 de dezembro de 1970. 16. ed. Tradução Laura F. de A. Sampaio. São Paulo: Loyola, 2008. p. 56.

40 LACLAU, Ernesto. A política e os limites da modernidade. In: HOLLANDA, Heloísa B. Pós-modernismo e política. Rio de Janeiro: Rocco, 1991. p. 127-150.

41 Idem.

42 BRITO, Diná T. de. Linguagem: o poder no discurso jurídico. Diálogo e Interação, Paraná, v. 1, 2009. Disponível em: <http://www.faccrei.edu.br/gc/anexos/diartigos14.pdf>. Acesso em: maio 2016.

43 PÊCHEUX, Michel. Semântica e discurso: uma crítica à afirmação do óbvio. Tradução Eni P. de Orlandi et alii. Campinas: Editora da UNICAMP, 1988.

44 BRITO, op. cit.

45 Idem.

46 BRITO, op. cit.

47 BRITO, op. cit.

48 Sargento da Polícia Militar do Meio Ambiente, entrevista março de 2015.

49 SOUZA, Jessé. A construção social da subcidadania: para uma sociologia política da modernidade periférica. Belo Horizonte: Editora da UFMG, 2006.

50 BOURDIEU, Pierre. O poder simbólico. Tradução Fernando Tomaz. 6. ed. Rio de Janeiro: Bertrand Brasil, 2003.

51 Idem.

52 BEBBINGTON, Anthony. Capitals and capabilities: a framework for analyzing peasant viability, rural livelihoods and poverty. World Development, United Kingdom, v. 27, n. 12, p. 2021-2044, 1999.

53 BOURDIEU, Pierre. O poder simbólico. Tradução Fernando Tomaz. 6. ed. Rio de Janeiro: Bertrand Brasil, 2003. p. 223.

54 BRASIL. Decreto-lei no 2.848, de 7 de dezembro de 1940. Código Penal. Diário Oficial da União (DOU), Rio de Janeiro, Seç. 1, p. 23911, 31 dez. 1940. (Publicação Original). Disponível em: <http://www.planalto.gov.br/ ccivil_03/decreto-lei/Del2848compilado.htm>. Acesso em: 14 maio 2015.

55 DWORKIN, Ronald. O império do direito. Tradução Jefferson Luiz Camargo. São Paulo: Martins Fontes, 2003.

56 BRASIL. Tribunal de Justiça do Estado de Minas Gerais. Inteiro teor dos acórdãos: leis especiais. Disponível em: $<$ http://www.tjmg.jus.br>.

57 NIEDERLE, Paulo André; GRISA, Catia. Diversificação dos meios de vida e acesso a atores e ativos: uma abordagem sobre a dinâmica de desenvolvimento local da agricultura familiar. Cuadernos de Desarrollo Rural, v. 5, n. 61, p. 41-69, 2008. Disponible en: <http://www.redalyc.org/articulo.oa?id=11713138002>. Acesso em: 16 maio 2016.

58 BOURDIEU, Pierre. O poder simbólico. Tradução Fernando Tomaz. 6. ed. Ri 


\title{
FAMILY FARMERS AS DEFENDANTS IN ENVIRONMENTAL JUDICIAL CASES: REFLECTIONS ON THE SYMBOLIC POWER OF THE LAW
}

\begin{abstract}
Farmers often face problems related to environmental legislation. This article aims at reflecting on the consequences of court proceedings in the lives of said farmers. The methodologies used were consultations and interviews. The main results show that the condition of vulnerability that affects these farmers, from both a social and an economic point of view, extends to the judicial field. While there is the assumption that justice seeks to resolve issues with equality, it was found that the economically and socially disadvantaged groups are also the ones that are hit the hardest by the solution of the dispute.
\end{abstract}

Keywords: Environmental legislation. Family farmers. Judicial lawsuits. Symbolic power.

Submetido: 13 out. 2016

Aprovado: 12 maio 2017 